\title{
Imagining a Better Classroom: Infographics to Build Learning Communities
}

JENNIFER IBRAHIM, PHD ${ }^{1}$; ANNE FRANKEL, PHD²; JAMIE MANSELL, PHD 3

${ }^{1}$ Department of Health Services Administration and Policy, College of Public Health, Temple University

${ }^{2}$ Department of Social and Behavioral Sciences, College of Public Health, Temple University

${ }^{3}$ Department of Health and Rehabilitation Sciences, College of Public Health, Temple University

\begin{abstract}
Innovative new teaching techniques continue to grow, but a solid grounding in the basic elements of good teaching pedagogy and clear communication is also needed. The foundation of a classroom should be a learning community in which students and instructors share a safe space to learn new content, engage in activities to practice with course content and build skills, and evaluate progress towards course learning goals. Some instructors were not formally trained to teach in higher education and may use the materials that were handed down to them, but not truly know bow to develop their own course from the beginning. In this article, we use infographics as a tool to reimagine how to build a better classroom. The benefit of infographics is that a picture allows the instructor to interpret the image and adjust for their teaching style and the context of the course. Key elements of good teaching include course alignment, class planning, clear communication with students, and collaboration between the instructor and students. Moreover, Covid-19 has heightened awareness of the need for instructors to consider the individual student and ensure that they are set up for success in the context of the class and being a student more generally. We showcase a set of six infographics to demonstrate the use of this medium to develop a successful and enjoyable course and discuss how the infographics can guide the development of an evidence-based teaching approach.
\end{abstract}

\section{Introduction}

The Covid-19 pandemic forced instructors across all areas of higher education to reassess their approach to teaching and strategies for student learning. In March 2020, 1,102 universities across the U.S. moved their course offerings fully online, impacting more than 14 million college students nationwide. ${ }^{1}$ However, the time for a re-evaluation of our approach to teaching was long overdue ${ }^{2}$ - as they say, "necessity is the mother of invention." While we, the authors, did not invent strong teaching practices, we certainly did innovate. As we were forced to move to online teaching, we went back to the foundation of good teaching pedagogy with renewed interest in engaging with students, not lecturing to students. Lecturing to the computer screen only to see a dark void staring back when students were (hopefully) listening but did not have their cameras on was not enough for quality teaching. We needed to think about imagining a new classroom where we ignite student interest in the course, engage them in the content, and ensure that the students are learning what they need to be successful in the degree program and their future professions.

Students in the College of Public Health at Temple University come from across the Commonwealth and around the globe; many are first-generation college students and from a range of cultural and 
socioeconomic backgrounds. ${ }^{3}$ As instructors, we need a consistent way to bring them along together. We need to recognize the range of environments and previous educational experiences and work towards equity to help all students be on a similar footing. ${ }^{4}$ Teaching in the online environment during a global pandemic threw the disparities across our student population into stark relief, creating urgency around changing classroom approaches. ${ }^{5}$ In addition, we recognized that instructors were struggling with parallel issues as a result of the pandemic, including juggling work and home life, managing Zoom fatigue, and retaining focus. ${ }^{6-7}$

The purpose of this article is to use infographics as a means of sharing a different perspective on teaching and learning to help instructors better prepare meaningful and engaging class sessions. In May 2020, we developed a self-paced online teaching training to assist full-time faculty, adjunct faculty, and doctoral

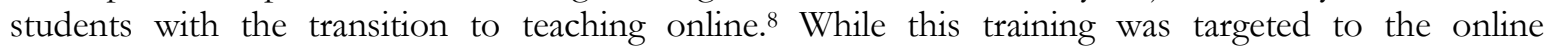
environment, many of the elements included were based on the fundamentals of sound teaching. In this article, we expand on that initial work and offer an evidence-based (but lighter-hearted) version of these ideas using images and infographics which can be effective in memorably communicating key ideas ${ }^{9}$ and helpful in processing complex concepts. ${ }^{10}$ The images cover everything from ways to assist our diverse student population to course planning principles, and from course implementation to providing overall support for student success.

We recognize that each reader will interpret the images a little differently, applying the concepts to a specific classroom context and ultimately creating meaningful learning and teaching experiences for students and instructors, alike. We encourage that. We hope that these images will resonate with every reader - and if they do, they will save them, download them, bookmark them, print them and hang them on a bulletin board. The images can be used to help plan a class or refer to when a class is not going as smoothly as expected, to get back to the basics. The approach is a guideline meant to facilitate instructor creativity with an evidence base, rather than be prescriptive. We offer six different infographic examples that walk an instructor through a class lifecycle including thinking about our student population, developing alignment when planning the course, establishing a classroom climate, planning out an individual class session, creating a collaborative learning community, and engaging in clear and supportive communication.

\section{Methods}

After we reviewed the existing literature surrounding pedagogy and best practices in teaching in higher education, we used a free software program (Canva) to create the infographics. (Note: Canva is one of many free platforms to create graphics that may be used in the classroom. Adobe is another great platform that may be freely available through an institution of higher education or available for purchase.) We first outlined key principles or ideas that we wanted to include and then developed images that would help the viewer remember the ideas presented. We used an iterative process for reviewing and refining to ensure that the images were user-friendly and easily interpreted.

\section{Results}

\section{Holistic Approach to Student Learning}

Before an instructor dives into a specific course, consideration for our overall student population is important. Diversity among our students helps to facilitate discussions and experiences that engage 
broader perspectives on an issue and allows all participants to learn from the experiences of others. However, the diversity of our audience means that as instructors, we need to consider the students more holistically. It is important to think about the student in the context of their financial, social, and physical environments. ${ }^{11}$ Are we setting the student up for success? Do we know if the students are working due to financial need or are they stressed out due to their living environment? As instructors, teaching the content is one component, but engaging the students and facilitating successful learning is a second (and very necessary) component. ${ }^{12}$ Without such consideration, the learning experience becomes frustrating for the student who is struggling and the instructor who can't understand where they are going wrong. For example, reflection on the student composition may result in students signing up for presentation times rather than being assigned, or office hours in person during the day and online in the evening. While this infographic is intended to help the instructor consider the needs of the students, it is also possible to use this infographic with students in an advising session or a class to help them to think about competing demands that may impact their performance in a class and ways to address them.

Figure 1 offers a holistic view of student success and is a reminder of the many different dimensions of a student's life that may contribute to their academic success. The figure is intended to bring awareness of the issues to the instructor, not to be prescriptive in action; a good supplement to this infographic could be a student resource guide, such as the Student Safety Nest. ${ }^{13}$ The financial aspect is one of the most important areas, as many students report struggling with paying tuition, purchasing textbooks, or needing technology. Has the student overcommitted between school, work, and home life, and do they need help with time management? Do they have a strategy for self-care, such as meditation or physical activity? Is the student struggling in class due to the need for accommodation based on their individual learning needs? Is the student struggling with their mental well-being or are they in an unsafe environment? The Covid-19 pandemic left many instructors feeling overwhelmed as we addressed so many more issues than class content. As instructors, we need to recognize the potential for these challenges and connect students with resources such as student financial services, scholarship avenues, emergency funds, educational resource services, temporary housing, and even food pantries. Instructors can also partner with academic advisors to assist students and provide follow-up. Student learning cannot occur solely in the confines of a class period, whether it is within four walls of a traditional classroom or the limits of a Zoom session. Academic success can start with recognizing these various issues and inviting students to connect if they need assistance.

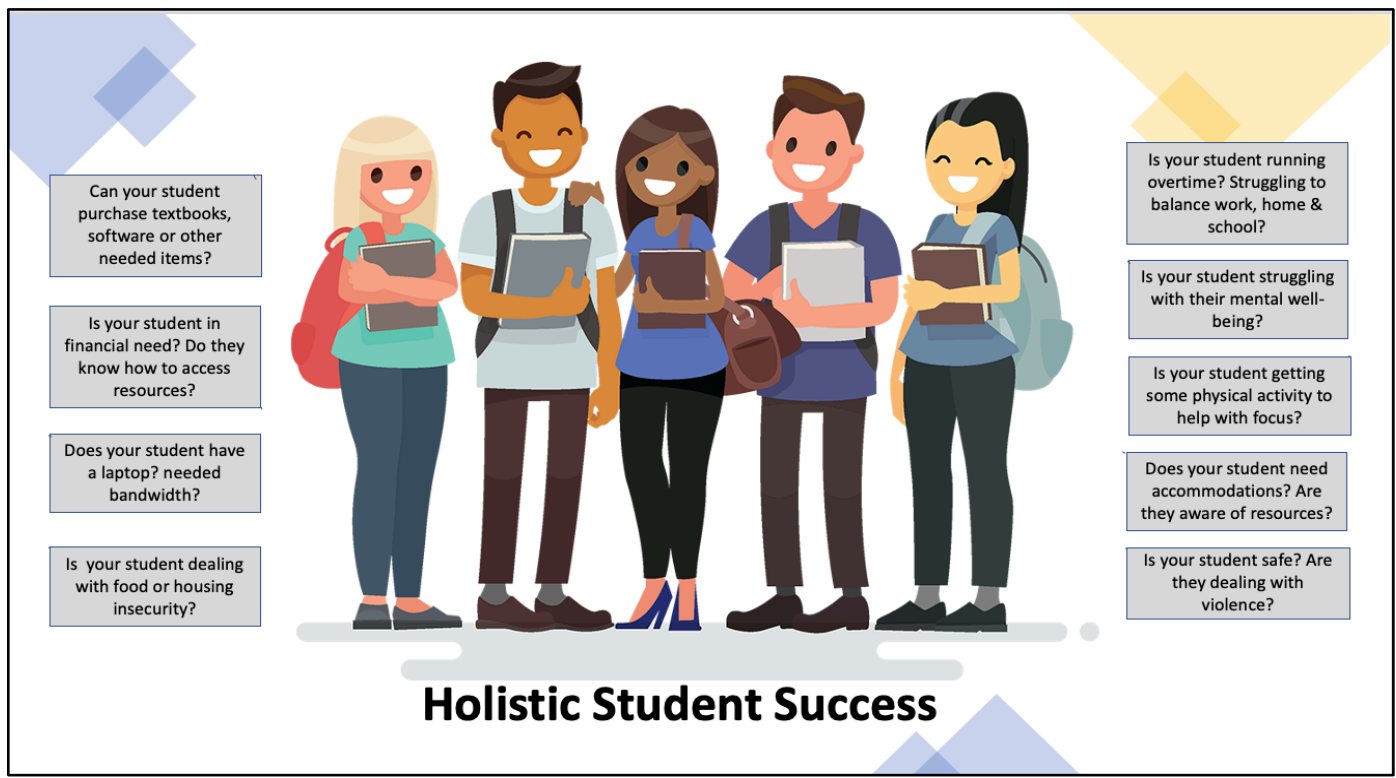

Figure 1: Considerations for Holistic Student Success 

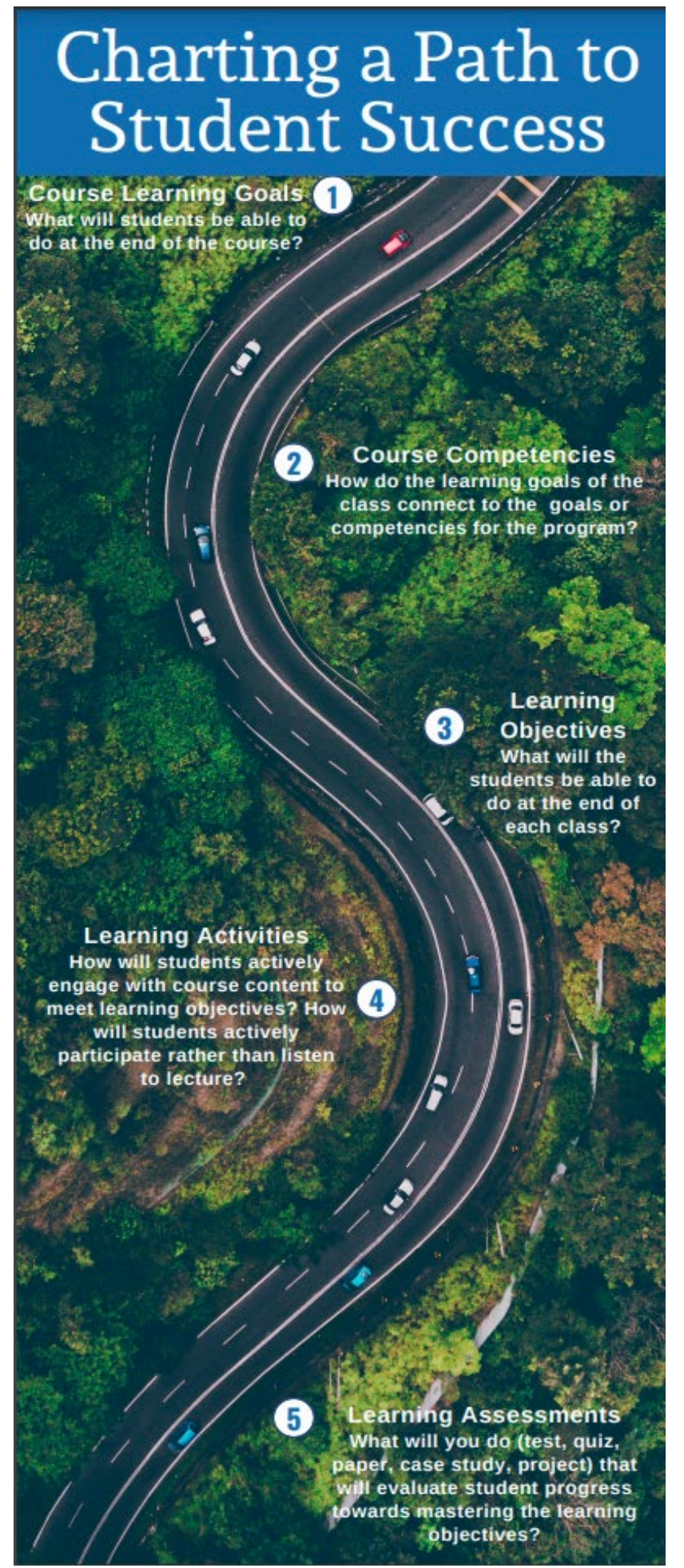

Figure 2: Charting a Path to Student Success: Course Alignment of Learning and Assessment

\section{Alignment in a Course}

Once we have acknowledged the audience with whom we will be working, it is time to dive into the course itself. When developing the course content, there must be a clear path that can be easily communicated to students - course alignment. The notion of integrated course design proposes alignment of three key components: learning goals, assessment, and teaching and learning activities. ${ }^{14}$ Given the range of accreditation standards required for many degree programs, we must meet those standards but also have an intentional plan for the course so that elements are connected. We must consider the course incrementally and provide students with the opportunity to reflect on prior knowledge, acquire new knowledge, practice retrieving new information for longer-term retention, connecting content with personal and realworld experiences, explaining what they have learned, and inspiring them to be lifelong learners. ${ }^{15}$

One way to think about course alignment is a roadmap (see Figure 2). The journey starts with considering course goals and setting expectations for what students will be able to do after the course. Next, think about how those course goals align with any learning standards or accreditation competencies (keeping in mind that accreditation requirements span a program and do not need to be packed into a single course.) A curriculum that introduces and reinforces content in multiple courses not only provides multiple perspectives but also creates deeper learning. Next, move to individual class sessions, weeks, or modules. The course has overall learning goals that can be broken down into the objectives that students will accomplish in each session. When there is a disconnect between what is being done in the class and why, it can create speed bumps, which may negatively impact student learning. ${ }^{16}$ Next, plan how to engage students with activities that will allow them to practice the skills or apply the content they have learned. ${ }^{17}$ Much like planning a journey, 
developing a class session requires looking at the big picture, including consideration of the number of students, the format and frequency of class meetings, the content, and course learning goals. ${ }^{18}$ And finally, assess the students to see if they mastered the materials and met the course goals through a combination of formative and summative assessments. There is also a benefit to including low-stakes assignments that give students a chance to engage content and receive feedback from the instructor. By planning and aligning these different elements, the result is a smooth journey where both instructors and students know exactly where they are going... and why! Finally, while this infographic is intended to guide the instructor in planning a course, it is also possible to use this infographic and adapt it to present to the class to explicitly show them the journey that they will follow throughout the semester.

\section{Establishing a Class Climate}

With the course built out, it is time to plan the individual class sessions. When we walk into a business, we see signs that set expectations for individual behavior inside - "no shirt, no shoes, no service," "no smoking," and even hours of operation. Clearly communicating expectations for being part of the classroom is no different. When it comes to teaching, we need to create a climate in which students can learn, taking into consideration the nature of interactions among class participants, the tone, language, and respect for the range of perspectives that will be shared. ${ }^{11}$ When we establish a class climate, it also provides focus and may help to minimize distractions for students. ${ }^{19}$

By creating a simple background image with "ground rules" (see Figure 3), we can communicate our expectations and etiquette for the course - and we can invite students to play a role in developing those expectations. The notion of a learning community can be emphasized by inviting students to develop elements of the expectations to which they will hold one another accountable. As the semester progresses, if the rules need to be adapted, it is easy to modify the image and replace the older version. If we are teaching online, we can use the image as the background in Zoom. If we are teaching in person, we can leave the image up on the screen during discussions. Either way, this basic graphic can create a culture that can help students learn in a safe space. The process can also help students to recognize the importance of professionalism in their interactions with others, which will assist them in their future careers.

\section{Class Ground Rules}

- No assumptions

- Be respectful of other perspectives/opinions

- Be open to feedback

- Questions are welcome!

- Learn from each other

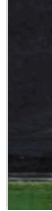

Figure 3: Developing Class Ground Rules
- "Promise to hear me, I promise to her you"

- Speak your mind and keep it real!

- Make space for everyone to participate

- Have fun and enjoy! 


\section{Planning a Class Session}

The process of developing each class can often be a major challenge; there is so much to cover and so little time. Planning a class session is sometimes like going to a favorite restaurant and thinking about what to eat. Is it a gourmet restaurant where a small but tasty bite goes a long way? Or is it the all-you-caneat buffet? A well-planned class is similar to a well-planned and well-balanced meal (Figure 4). It is important to include breaks in the class to retain student focus ${ }^{19}$ and to break the content down into chunks (no more than about 12 minutes per topic) to help students with processing material. ${ }^{20}$ By using a variety of different teaching strategies such as lectures, breakout discussions, case studies, worksheets, polling questions, and many more approaches, ${ }^{17}$ the class session remains interesting for students and the instructor alike.

Start the class off with the "appetizer." Engaging students in a short activity is a great way to get them focused on the class and leave behind the problems of the day or a list of todos that were on their minds just before the class. We can interest students in the topic of the day with a short activity to get their brains warmed up and ready to learn. Once the students are hungry for learning, shift to the main meal: key elements that need to be covered. Consider how to balance those elements throughout the session; it is important to have active learning opportunities to demonstrate how the content being presented can be used in a practical context. ${ }^{11}$ Short breaks - even a 2 -minute stretch break - can help students remain focused. ${ }^{19}$ Also, remembering alignment and thinking about learning objectives and how to assess student learning during the session is important; this can be a low-stakes or nostakes assignment, but it helps students to see how they are doing. And don't forget dessert: wrap up the class session with a reward. When the students worked hard throughout the class and were active participants, acknowledge that good work concretely; this could include a

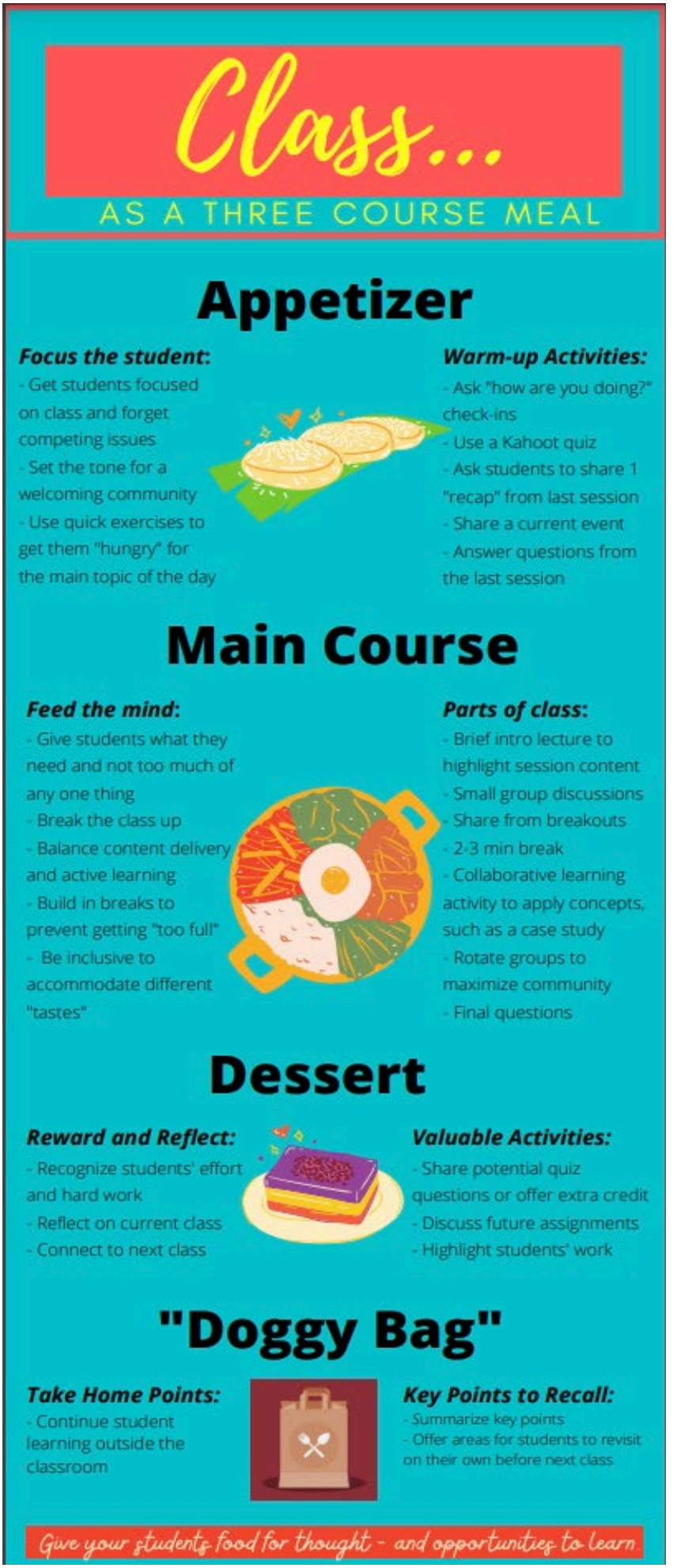

Figure 4: Understanding Class as a Three Course Meal 
recap of interesting points made and highlighting how the current class will springboard to the next session. It is also possible to offer resources as a reward for a good class such as potential future quiz questions or sharing an example of a model assignment. Finally, help the student pack their "doggy bag"what are the key take-home points from class and what is next on the menu for them to complete? And much like leaving a tip in relation to the service provided at a restaurant, we can ask students to provide feedback through student feedback forms or direct feedback to the instructor.

While this infographic is intended for the instructor as a guide while preparing a class session, it is also possible for the instructor to adapt the infographic to a particular class session by tailoring the items on the right side of the class to the specific session. For the appetizer, add a Kahoot competition on a specific topic or a reflection question to get the students warmed up. For the main course, break down the different elements of the class session such as a lecture on the policymaking process, a group discussion on a new bill introduced in Congress, and then a policy analysis exercise on that bill. For the dessert, share an example of policy analysis on the bill that was conducted by an advocacy organization and ask the students to think about how it connects with the next class on policy implementation. And for the doggy bag, encourage students to seek out an emerging policy that is important to them and invite them to share it during the next class.

\section{Collaborating in the Classtoom}

“Online teaching isn't for me! I like to feel connected to my students, and I cannot do that behind a screen." This quote is something that resonates with many of us. It's something that we have heard many times since the transition to online teaching in the pandemic. While barriers exist in an online platform and in the physical classroom - instructors should intentionally build opportunities for collaboration and community-building into every course from the outset (Figure 5). There is evidence that collaboration leads to increased engagement and higher-level thinking. ${ }^{21}$

How do we intentionally add collaboration in our classes? Before a class session, send out an agenda or worksheets for the day so that students know what to expect and invite students to share any questions in advance. A quick email or Canvas note is just enough to help students plan to be prepared for class. During the class, create avenues for nurturing student communication skills and openness to learning from one another. By facilitating interactions between students during class time - rather than just observing a lecture - students will engage with the content and have a longer-lasting learning experience. If the course has group projects, some dedicated time for check-in and group work can encourage collaboration to continue outside the class. The use of group contracts to set clear expectations within peer groups is a sound method to set expectations, define processes, and assign responsibilities. Finally, encourage student learning to continue outside the class by inviting students to office hours or challenge them to apply what was just learned to a "real world" issue. 
Building Course Collaboration

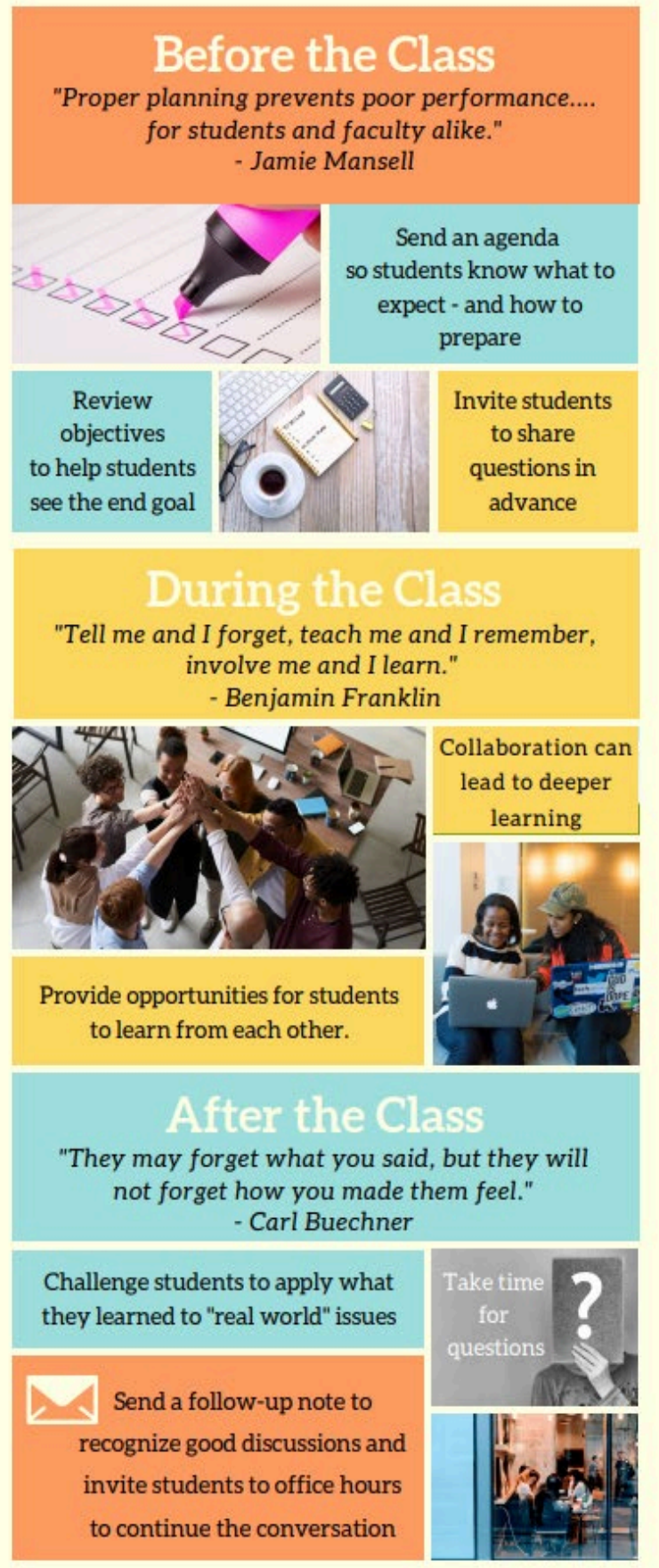

Figure 5: Building Course Collaboration

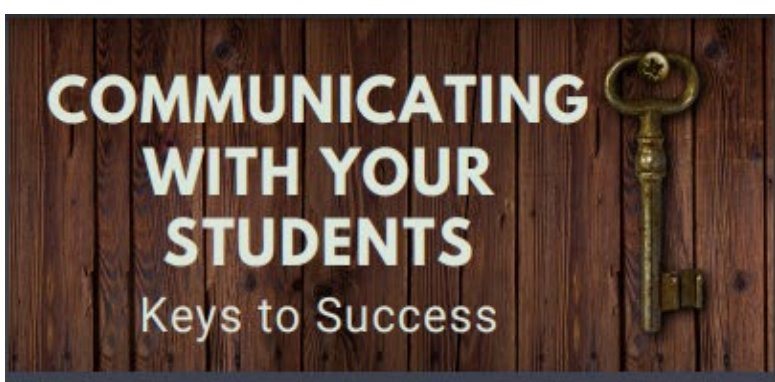

Clear, supportive communication is critical when sharing information, releasing assignments, providing feedback and building a rapport with students to help them meet academic, personal, and professional goals.

\section{TONE}

Be sure you are intentional in your tone.

What tone does the message require? Is it friendly and inviting? Is it authoritarian?

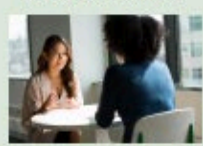

TIME

Be consistent and predictable.

How often do you communicate? What frequency is needed? Can you vary timing?

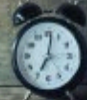

REAL

REALITY

Be your real self.

Remember students are people.

Do you talk about your family and your interests?

Do you share your thoughts?

Do you talk about current events?

Dou check-in with your students to see how they are doing? Do you create space for students to share their worlds?

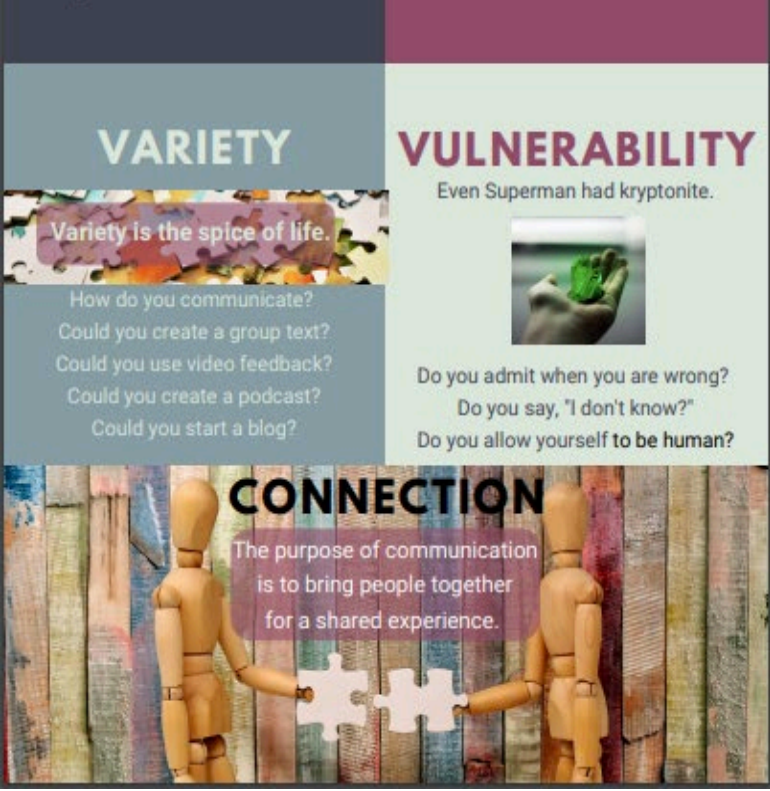

Figure 6: Communicating with Your Students 


\section{Communication with Students}

When we meet a new person for the first time, we have mere seconds to make a first impression. But when we are teaching, how can we make an impression on our students that we may see in-person or online? Often, it's through our very first communication: an email, an introductory video, an announcement, or however we start a new class. Taking the time to think intentionally about that first connection can make a huge difference in the climate of the class throughout the semester.

When planning a communication (see Figure 6), we first consider the tone, aiming to balance firmness with friendliness and support. There's a world of difference between admonishing students for poor performance and recognizing performance while offering avenues for improvement. We can vary the timing and type of communication with students. While students can benefit from a consistent communication schedule (think Monday morning announcements, or an email wrap-up right after class), it is also possible to adjust communications to best meet the needs of students. For example, if there are a lot of written communications on a strict schedule, sending out a video with tips for success while students are working on a draft or preparing for a quiz is an alternative option. Trying different communication types can stave off student boredom: if they are familiar with course videos, a group chat or podcast may be a welcome change.

Once the tone, timing, and type of communication are planned, look carefully at the content. Considering the diverse needs of our students, try to reflect on personality and the reality of student life. Sharing parts of ourselves (within appropriate limits) can help students recognize that instructors are people too and will make regular check-ins about their well-being and progress feel more authentic. Finally, we can show vulnerability in our communication. It's ok for us to say "I don't know", and share with students our successes and failures. Modeling growth and determination can inspire our students to find their own growth.

It's been said that we never get a second chance to make a first impression. That may be true, but as instructors, we have many opportunities to communicate with our students throughout the semester. Keep revisiting the structure, content, and timing of communication to keep students informed, engaged, and supported. When we use our course communications to connect with students, we can convey warmth and empathy while also increasing student's self-efficacy to succeed - elements that have a significant impact on student engagement and learning. ${ }^{22}$

\section{Conclusion}

Teaching needs to stay fresh for student attention and instructor retention. We each have our approach to teaching and our own teaching philosophies, but all teaching should be based on sound pedagogy and evidence-based techniques. Using infographics such as the ones presented here is a way to level all instructors to the foundational elements of good teaching and still leave room for innovation and tailored approaches; this makes us more than the sum of our parts and offers a holistic and integrated learning experience. It certainly takes time to create an engaged learning community, but that community can foster an improved learning experience for students and satisfying teaching experiences for instructors. We hope that instructors will use these infographics as a springboard to create revised or new versions for use within their own learning communities. (Note: All infographics are available for use upon request to the authors.) 


\section{Disclosures and Conflicts of Interest}

Dr. Ibrahim is a Faculty Editor of CommonHealth.

\section{References}

1. Hess, A. (2020). How coronavirus dramatically changed college for over 14 million students.

2. Mintz, S. (2021, February). Let's not return to the old normal. Inside Higher Ed.

3. Temple University Institutional Research and Assessment. (2019). Temple University At-AGlance, 2019-2020.

4. Dosch, M., \& Zidon, M. (2014). "The course fit us": Differentiated instruction in the college classroom. International Journal of Teaching and Learning in Higher Education, 26(3), 343357.

5. Fain, P. (2020, June). Higher education and work amid crisis. Inside Higher Ed.

6. Flaherty, C. (2020, November). Faculty pandemic stress is now chronic. Inside Higher Ed.

7. Nietzel, M. T. (2021, February). Pandemic toll: More than half of college faculty have considered a career change or early retirement. Forbes.

8. Frankel, A. S., Friedman, L., Mansell, J., \& Ibrahim, J. K. (2020). Steps towards success: Faculty training to support online student learning. Journal of Faculty Development, 34(2), 2332.

9. Alrwele, N. S. (2017). Effects of infographics on student achievement and students' perceptions of the impacts of infographics. Journal of Education and Human Development, 6(3), 104-117.

10. Naparin, H., \& Saad, A. B. (2017). Infographics in education: Review of infographics design. International Journal of Multimedia \& ITs Applications, 9(4), 15-24. https:// doi.org/10.5121/ijma.2017.9602

11. Ambrose, S. A., Bridges, M. W., DiPietro, M., Lovett, M. C., \& Norman, M. K. (2010). How learning works: Seven research based principles for smart teaching. Jossey-Bass.

12. Lipka, S. (2020). How 5 experts say colleges can create a 'bolistic' student experience. The Chronicle of Higher Education.

13. Temple University Dean of Students. (2021). Student Safety Nest.

14. Fink, L. D. (2002). A self-directed guide to designing courses for significant learning.

15. Lang, J. M. (2016). Small Teaching: Everyday Lessons from the Science of Learning. Jossey-Bass.

16. Barrett, C. (2017, May). "Why do I need to know this?" Faculty Focus.

17. Davis, B. G. (2009). Tools for teaching. Jossey-Bass.

18. CAST. (2018). Universal design for learning guidelines version 2.2. https://udlguidelines.cast.org/

19. Lang, J. M. (2020). Distracted: Why students can't focus and what you can do about it. Basic Books.

20. Fountain, S. B., \& Doyle, K. E. (2012). Learning by chunking. Encyclopedia of the Sciences of Learning. https://doi.org/https://doi.org/10.1007/978-1-4419-1428-6_1042

21. Hodges Persell, C. (2004). Using focused web-based discussions to enhance student engagement and deep understanding, Teaching Sociology, 32(1), 61-78.

22. Darby, F., \& Lang, J. M. (2019). Small teaching online: Applying learning science in online classes. Jossey-Bass.

\section{Statement of Contributions}

All three authors worked together to develop the concepts, create the infographics, draft the manuscript, and complete edits to the manuscript. 